\title{
Comparison of osteoclastogenesis and local invasiveness of ameloblastoma and keratocystic odontogenic tumor
}

\author{
Natheer H. Al-Rawi ${ }^{1}$, Ammar K. Al-Siraj², Ahlam H. Majeed ${ }^{2}$
}

Correspondence: Dr. Natheer H. Al-Rawi

'Department of Oral and Craniofacial Health Sciences College of Dental Medicine, University of Sharjah, Sharjah, United Arab Emirates,

Email: nhabdulla@sharjah.ac.ae

2Department of Oral Diagnosis, College of Dentistry, University of Baghdad, Baghdad, Iraq

\section{ABSTRACT}

Objectives: The aim of this study was to compare the expression of receptor-activated nuclear factor kappa B (RANK) with its ligand (RANKL) and matrix metalloproteinase-2 (MMP2) in solid/multicystic ameloblastomas (ABs) and keratocystic odontogenic tumors (KOTs). Materials and Methods: The expression of MMP2, RANK, and RANKL molecules was evaluated in $13 \mathrm{ABs}$ and 14 KOTs by immunohistochemistry. The expressions were calculated in the odontogenic epithelial cells as well as the stromal cells. Results: Odontogenic epithelia of AB expressed MMP2, RANK, and RANKL significantly higher than that of KOTs $(P<0.05)$. The expression of MMP2, RANK, and RANKL was highest in plexiform subtype $(79.9 \%$, $81.08 \%$, and $65.1 \%$, respectively). KOTs without daughter epithelia nests expressed both MMP2 and RANK the least (56.06\% and $47.5 \%$, respectively). Stromal cells, on the other hand, expressed similar MMP2 pattern in odontogenic epithelia of both $\mathrm{AB}$ and KOT. RANKL was expressed weaker in the stromal cells of both lesions. Conclusion: Invasive biological and osteolytic behaviors of both lesions were evaluated in this study. It was found to be more in AB than keratocystic odontogenic. A significant expression of MMP2, RANK, and RANKL in both KOTs associated with microcyst and plexiform type AB as well.

Key words: Keratocystic odontogenic tumor, matrix metalloproteinase-2, odontogenic keratocysts, receptor-activated nuclear factor kappa B, receptor-activated nuclear factor kappa B ligand, solid/multicystic ameloblastoma

\section{INTRODUCTION}

Keratocystic odontogenic tumors (KOTs) and ameloblastoma $(\mathrm{AB})$ are characterized by slow growth with locally invasive behavior and high risk of recurrence. ${ }^{[1]}$ Both show infiltration into cancellous bone and destructive growth. That is why in 2005, odontogenic keratocyst is renamed as "KOTs" by the World Health Organization. ${ }^{[2]}$ The receptor-activated nuclear kappa $\mathrm{B}$ (RANK) is a central activator of necrosis factor-kappa B, which controls the transcription of DNA, and is the signaling receptor for RANK

\begin{tabular}{|l|l|}
\hline \multicolumn{3}{|c|}{ Access this article online } \\
\hline Quick Response Code: \\
\hline
\end{tabular}

ligand (RANKL). RANKL binds to RANK on the surface of preosteoclasts and stimulates the development and activation of osteoclasts. ${ }^{[3]}$ Many authors suggested that odontogenic epithelial cells are an important source of RANK. ${ }^{[4,5]}$ Sandra et al..$^{[6]}$ suggested that AB could induce osteoclastogenesis by secreting RANKL and tumor necrosis factor $\alpha(\mathrm{TNF}-\alpha)$. da Silva et al. ${ }^{[5]}$ in their study on $\mathrm{AB}$ and odontogenic keratocyst (OKC) found that $>90 \%$ of odontogenic epithelium of both

This is an open access article distributed under the terms of the Creative Commons Attribution-NonCommercial-ShareAlike 3.0 License, which allows others to remix, tweak, and build upon the work non-commercially, as long as the author is credited and the new creations are licensed under the identical terms.

For reprints contact: reprints@medknow.com

How to cite this article: $\mathrm{Al}-\mathrm{Rawi} \mathrm{NH}, \mathrm{Al}-\mathrm{Siraj} \mathrm{AK}$, Majeed $\mathrm{AH}$. Comparison of osteoclastogenesis and local invasiveness of ameloblastoma and keratocystic odontogenic tumor. Eur J Dent 2018;12:36-42.

DOI: 10.4103/ejd.ejd 54 17 
lesions expressed RANK. They suggested that RANK originating from odontogenic epithelium enhances bone resorption due to its effect on tumor growth, cell proliferation, or delaying apoptosis. MMP2 is a gelatinase of the matrix metalloproteinase (MMP) family. It degrades many types of collagens such as native type IV, $\mathrm{V}$, and $\mathrm{X}$ collagen and denatured fibrillar type I, II, and III collagens. ${ }^{[7]}$ It has been found that many members of MMP family take part in cancer invasion and metastasis. ${ }^{[8]}$ Interest in $\mathrm{AB}$ and KOTs has risen due to their aggressive clinical behavior, variety of morphological patterns, and high recurrence rates. Since these tumors generally exhibit localized bone destruction and tooth resorption, the differential expressions of MMP2, RANK, and RANKL may be expected to find in these lesions. The aim of the present study is to examine and evaluate the expression of MMP2, RANK, and RANKL in both lesions, in an attempt for better understanding of biological behavior associated with these odontogenic tumors from the points of invasiveness and osteoclastogenesis.

\section{MATERIALS AND METHODS}

\section{Tissue samples}

The study was approved by the Research and Ethics Committee of College of Dentistry at University of Baghdad (REC. 25-2014). The paraffin blocks were retrieved from the archives of the Oral Diagnosis Department, College of Dentistry, University of Baghdad. The diagnosis of each case was confirmed by two oral pathologists through the examination of hematoxylin and eosin-stained sections. Data, regarding name, age, sex, and site of the lesion, were collected from the routine histopathology files of the same cases. Recurrent $\mathrm{AB}$ and KOTs were excluded from the study.

The expression of MMP2, RANK, and RANKL was evaluated in the tissue specimens of 14 KOT and 13 solid/multicystic AB (SMA). The SMA was subdivided into eight follicular and five plexiform patterns, while KOTs were categorized into those associated with daughter epithelial nests (KOT with + dentigerous cyst [DC]) group $(n=5)$ and those without (KOT with - DC) group $(n=9)$. All tests were carried out on $4 \mu \mathrm{m}$ sections from formalin-fixed paraffin-embedded blocks of SMA and KOT. The expressions were calculated in the odontogenic epithelial cells as well as the stromal cells.

\section{Immunohistochemical staining}

The paraffin blocks were cut serially into approximately $5 \mu \mathrm{m}$ thick sections on charged slides. Using Dako
Autostainer, the slides were deparaffinized with xylene for $30 \mathrm{~min}$, washed with absolute 100\% alcohol for $15 \mathrm{~min}$, and then washed with 95\% alcohol and distilled water. Dako REAL ${ }^{\mathrm{TM}}$ EnVision $^{\mathrm{TM}}$, peroxidase/diaminobenzidine (DAB), and Mouse IG detection system were used for MMP2, RANK, and RANKL. For antigen retrieval, 20-min heat-induced antigen retrieving was performed with RANK and RANKL, while in MMP2, enzyme block solution was used only (chemical retrieving). The retrieving solution used for RANK and RANKL was citrate buffered $\left(\mathrm{pH}=9\right.$ under $80^{\circ} \mathrm{C}$ for RANKL and $\mathrm{pH}=6$ under $85^{\circ} \mathrm{C}$ for RANK) and then washed in phosphate buffered saline for $5 \mathrm{~min}$. To block endogenous peroxidase activity, slides were incubated with $3 \%$ hydrogen peroxide, washed in distilled water and then soaked in phosphate buffer saline for $5 \mathrm{~min}$.

MMP2 antibody at a dilution of 1:50 (Abcam No: Ab3158, Monoclonal Mouse Anti-Human MMP2 Antigen, CA-4001/7CA19E3C, Abcam, USA), RANK antibody at a dilution of 1:50 (Abcam No: Ab12008, Monoclonal Mouse Anti-Human MMP2 Antigen, 9A725, Abcam, USA), and RANKL at a dilution of 1:75 (Abcam No: Ab 45039, Monoclonal Mouse Anti-Human RANKL Antigen, 12A668, Abcam, USA) were used as primary antibodies. Slides were incubated overnight at $4^{\circ} \mathrm{C}$ with MMP2, RANK, and RANKL. Positive control slides were obtained according to the antibodies manufacturer's data sheet. For MMP2 monoclonal antibodies, tissue blocks of breast carcinoma were used. ${ }^{[7]}$ For RANK, the bone tissue located at the periphery of the lesions of SMA and KOT was used, while that for RANKL, tissue blocks of peripheral giant cell granuloma were used..$^{[5]}$ The negative control slides were prepared by substituting the primary specific antibodies with nonimmune serum. All the above control samples were fixed and processed in a way similar to that of test samples. The secondary antibody Dako REAL ${ }^{\mathrm{TM}}$ EnVision ${ }^{\mathrm{TM}} / \mathrm{HRP}$, Rabbit/Mouse IgG was reacted for $30 \mathrm{~min}$, followed by DAB-chromogen solution for $30 \mathrm{~min}$ being used to visualize the reaction. Finally, the sections were 0counterstained with Mayer's hematoxylin, dehydrated, coverslipped, and evaluated by light microscopy.

Signal specificity was demonstrated by the absence of immunostaining in the negative control slides and its presence in the recommended positive controls. Odontogenic epithelia and stromal cells in both SMA and KOT with clear brown membranous/ cytoplasmic staining were considered to be positive for MMP2, RANK, and RANKL immunostaining within a violet-blue tissue section background of 
hematoxylin staining. All the slides were assessed blindly by two pathologists without prior knowledge of the corresponding clinicopathological data, and the average of the two readings was obtained.

The specimens were examined and counted at $\times 200$ magnification using integration graticule with an Olympus $C \times 30$ microscope. In the epithelia, positive cells were counted in five contiguous and consecutive microscopic high-power fields. In the stroma, positive endothelial and fusiform cells (fibroblasts) were quantified in five contiguous and consecutive areas adjacent to neoplastic odontogenic epithelium; $; 5,9]$ each field of the integration graticule had an area of $0.0061 \mathrm{~mm}^{2} \cdot{ }^{[9]}$ For accuracy, the counting rechecked at $\times 400$ for each field. Results were obtained and the mean of the percentage of positive cells was determined for each representative field.

Statistical analyses were done using SPSS version 21 (Chicago., IL, USA). The statistical significance of differences in RANK, RANKL, and MMP 2 reactivity was analyzed in both lesions by the Mann-Whitney U-test and $P<0.05$ was considered to indicate statistical significance.

\section{RESULTS}

The demographic data of the studied sample are shown in Table 1. The mean age of patients from which the $\mathrm{AB}$ specimens were obtained ranged between 10 and 45 years (mean $=30.6$ years). For KOT cases, the age range was between 15 and 45 years (mean $=31.9$ years). All cases of AB occurred in the mandible, and for KOT, the mandible was more frequently involved than maxilla (64.3\% and $35.7 \%$, respectively) [Table 1].
MMP2, RANK, and RANKL immunostaining was detected in the odontogenic epithelial cells as well as in the stromal cells.

\section{Matrix metalloproteinase-2 immunostaining}

Strong expression of MMP2 was seen in ABs and KOTs, with higher value in SMA tumor cells than keratocyst lining epithelia $(73.29 \%$ and $63.87 \%$, respectively). However, the difference was not statistically significant $(P=0.09)$ [Table 2]. MMP2 expression was higher in epithelial cells of plexiform AB (79.9\%), followed by KOT associated with daughter epithelia nests $(76.37 \%)$ and then follicular AB (68.57\%), and the least was in KOT not associated with daughter epithelial nests (56.06\%) as shown in Figure 1 and Table 3. MMP2 expression in stromal cells was almost the same in SMA and KOT $(48.66 \%$ and $50 \%$, respectively), with no significant differences between the histological subgroups [Table 2].

\section{Receptor-activated nuclear factor kappa B immunohistochemical staining}

Odontogenic epithelial cells of AB strongly expressed RANK, which is significantly higher than that of KOT $(67.55 \pm 16.83$ versus $51.8 \pm 17.15)$ as seen in Table 4 and Figure 2, whereas RANK expression in stromal cells did not show any significant differences between lesions.

Plexiform AB highly expressed RANKL in their odontogenic epithelium in $81.08 \%$, followed by follicular type $(62 \%)$, KOT associated with daughter epithelia nest (58.7\%), and then KOT with no daughter epithelia nest group (47.5\%). A statistically significant difference was seen only when plexiform pattern

\begin{tabular}{|c|c|c|c|c|c|c|c|c|}
\hline & \multirow[t]{2}{*}{$n$} & \multicolumn{2}{|c|}{ Sex } & \multicolumn{3}{|c|}{ Age } & \multicolumn{2}{|c|}{ Site } \\
\hline & & Male (\%) & Female (\%) & Range & Mean $\pm S D$ & SE & Mandible (\%) & Maxilla (\%) \\
\hline$A B$ & 13 & $7(53.8)$ & $6(46.2)$ & $10-45$ & $30.6 \pm 9.16$ & 2.64 & $13(100)$ & 0 \\
\hline KOT & 14 & $6(42.9)$ & $8(57.1)$ & $15-45$ & $31.9 \pm 8.94$ & 2.38 & $9(64.2)$ & $5(35.7)$ \\
\hline
\end{tabular}

\begin{tabular}{|c|c|c|c|c|c|c|c|}
\hline Tissue group & Cells & Total number & Positive MMP2 & Negative MMP2 & Mean $\pm S D$ & SE & $P$ \\
\hline$\overline{S M A}$ & Odontogenic epithelium & 13 & 12 & 1 & $73.29 \pm 10.92$ & 3.16 & 0.09 \\
\hline КOT & & 14 & 13 & 1 & $63.87 \pm 16.36$ & 4.53 & \\
\hline SMA & Stromal cells & 13 & 12 & 1 & $48.66 \pm 12.03$ & 3.47 & 0.7 \\
\hline KOT & & 14 & 13 & 1 & $50.00 \pm 14.69$ & 4.07 & \\
\hline
\end{tabular}

MMP2: Matrix metalloproteinase-2, SMA: Solid/multicystic ameloblastoma, KOT: Keratocystic odontogenic tumor, SD: Standard deviation, SE: Standard error 
Table 3: Comparison between matrix metalloproteinase-2 area percentage in the odontogenic epithelia and stromal cells of follicular ameloblastoma, plexiform ameloblastoma, keratocystic odontogenic tumor (negative dentigerous cysts), and keratocystic odontogenic tumor (positive dentigerous cysts)

\begin{tabular}{|c|c|c|c|c|c|c|c|}
\hline Tissue group & Cells & Total number & Positive MMP2 & Negative MMP2 & Mean \pm SD & SE & $P$ \\
\hline Follicular $\mathrm{AB}$ & Odontogenic epithelia & 8 & 7 & 1 & $68.57 \pm 8.52$ & 3.22 & 0.06 \\
\hline Plexiform $A B$ & & 5 & 5 & 0 & $79.9 \pm 11.29$ & 5.05 & \\
\hline KOT (negative DC) & & 9 & 8 & 1 & $56.06 \pm 9.56$ & 3.38 & $0.01^{*}$ \\
\hline KOT (positive DC) & & 5 & 5 & 0 & $76.37 \pm 18.65$ & 8.07 & \\
\hline Follicular AB & Stromal cells & 8 & 7 & 1 & $52.57 \pm 4.98$ & 1.88 & 0.16 \\
\hline Plexiform AB & & 5 & 5 & 0 & $43.2 \pm 17.23$ & 7.70 & \\
\hline KOT (negative DC) & & 9 & 8 & 1 & $46.87 \pm 13.15$ & 4.65 & 0.3 \\
\hline KOT (positive DC) & & 5 & 5 & 0 & $55.0 \pm 17.16$ & 7.67 & \\
\hline
\end{tabular}

*Significant at $P \leq 0.05$. AB: Ameloblastoma, KOT: Keratocystic odontogenic tumor, SD: Standard deviation, SE: Standard error, MMP2: Matrix metalloproteinase-2, DC: Dentigerous cysts

Table 4: Comparison between receptor-activated nuclear factor kappa B area percentage of the odontogenic epithelia of solid/multisystem ameloblastoma and keratocystic odontogenic tumor

\begin{tabular}{|c|c|c|c|c|c|c|c|}
\hline Tissue group & Total number & Cells & Positive RANK & Negative RANK & Mean $\pm S D$ & SE & $P$ \\
\hline SMA & 13 & Odontogenic epithelia & 12 & 2 & $67.55 \pm 16.83$ & 5.07 & $0.02^{*}$ \\
\hline KOT & 14 & & 13 & 1 & $51.8 \pm 17.15$ & 4.75 & \\
\hline SMA & 13 & Stromal cells & 10 & 3 & $45.22 \pm 18.74$ & 5.92 & 0.59 \\
\hline KOT & 14 & & 13 & 1 & $41.34 \pm 18.49$ & 5.13 & \\
\hline
\end{tabular}

*Significant at $P \leq 0.05$. RANK: Receptor-activated nuclear factor kappa B, SMA: Solid/multicystic ameloblastoma, KOT: Keratocystic odontogenic tumor, SD: Standard deviation, SE: Standard error

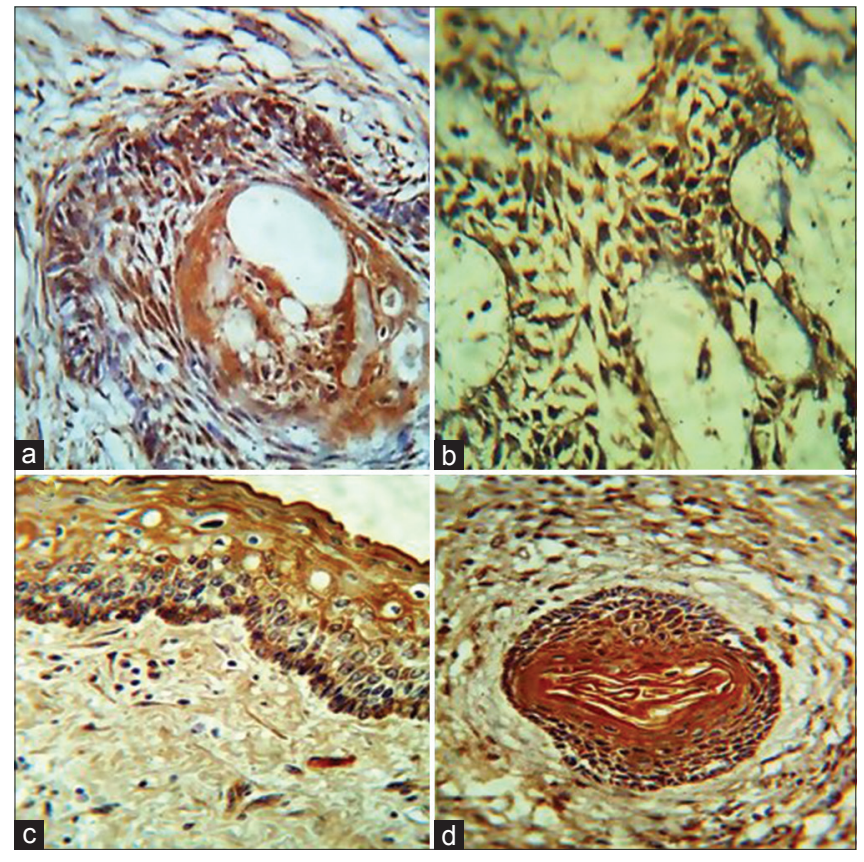

Figure 1: (a-d) Matrix metalloproteinase-2 expression in odontogenic epithelium, follicular ameloblastoma, plexiform ameloblastoma, keratocystic odontogenic tumor (-dentigerous cysts), keratocystic odontogenic tumor (+dentigerous cysts)

compared with both subtypes of KOT $(P=0.03$ and $P=0.009$, respectively) [Table 5]. In the stroma, the expression was almost similar with a bit elevation of SMA $(45.22 \%$ and $41.34 \%)$ [Table 4 ].

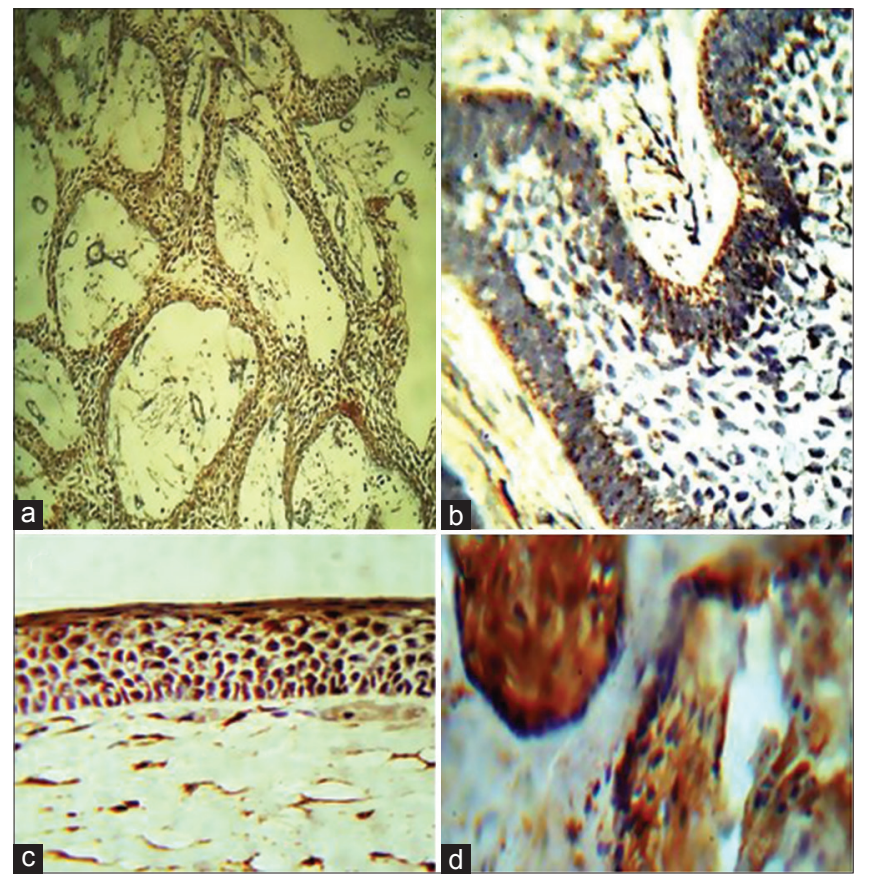

Figure 2: (a-d) Receptor-activated nuclear factor kappa B expression in odontogenic epithelium, follicular ameloblastoma, plexiform ameloblastoma, keratocystic odontogenic tumor (-dentigerous cysts), keratocystic odontogenic tumor (+dentigerous cysts)

Receptor-activated nuclear factor kappa B ligand immunostaining

In this study, RANKL was detected in the membrane and cytoplasm and in the extracellular of $\mathrm{AB}$ and $\mathrm{KOT}$ cells as seen in Figure 3. 


\begin{tabular}{|c|c|c|c|c|c|c|c|}
\hline Tissue group & Total number & Cells & Positive RANK & Negative RANK & Mean $\pm S D$ & SE & $P$ \\
\hline Plexiform AB & 5 & Odontogenic epithelia & 3 & 2 & $81.08 \pm 3.74$ & 2.16 & $0.03^{*}$ \\
\hline Follicular AB & 8 & & 8 & 0 & $62.48 \pm 17.11$ & 6.05 & \\
\hline KOT (negative DC) & 9 & & 8 & 1 & $47.5 \pm 16.87$ & 5.96 & 0.25 \\
\hline KOT (positive DC) & 5 & & 5 & 0 & $58.7 \pm 16.97$ & 7.59 & \\
\hline Plexiform AB & 5 & Stromal cells & 3 & 2 & $38.33 \pm 2.88$ & 1.66 & $0.009^{\star *}$ \\
\hline Follicular $\mathrm{AB}$ & 8 & & 8 & 0 & $48.17 \pm 2.14$ & 8.36 & \\
\hline KOT (negative DC) & 9 & & 8 & 1 & $48.2 \pm 14.53$ & 6.49 & 0.25 \\
\hline KOT (positive DC) & 5 & & 5 & 0 & $37.06 \pm 20.28$ & 7.17 & \\
\hline
\end{tabular}

*Significant at $P \leq 0.05,{ }^{*}$ Significant at $P \leq 0.01$. AB: Ameloblastoma, KOT: Keratocystic odontogenic tumor, SD: Standard deviation, SE: Standard error, RANK: Receptor-activated nuclear factor kappa B, DC: Dentigerous cysts

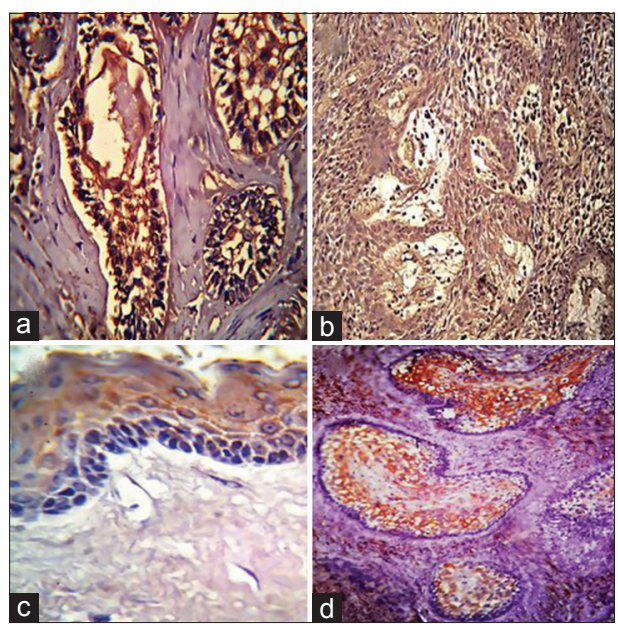

Figure 3: (a-d) Receptor-activated nuclear factor kappa B ligand expression in odontogenic epithelium, follicular ameloblastoma, plexiform ameloblastoma, keratocystic odontogenic tumor (-dentigerous cysts), keratocystic odontogenic tumor (+dentigerous cysts)

Epithelial cells of $\mathrm{AB}$ expressed more RANKL than that of KOT without reaching statistical significance $(P=0.06)$. However, stromal cells expressed RANKL more in AB than KOT with almost significant differences [Table 6].

Regarding histological subtypes, epithelia of plexiform type expressed more RANKL (65.1\%) than follicular type (53.53\%). Epithelial and stromal cells of KOT, on the other hand, showed almost same expression in both subtypes without observable statistical significant value [Table 7].

\section{DISCUSSION}

Assessment of matrix metalloproteinase-2 expression in ameloblastoma and keratocystic odontogenic tumor MMP2 plays a major role in extracellular matrix remodeling because of its ability to initiate and continue

\begin{tabular}{|c|c|c|c|c|c|c|}
\hline $\begin{array}{l}\text { Tissue } \\
\text { group }\end{array}$ & $\begin{array}{c}\text { Total } \\
\text { number }\end{array}$ & $\begin{array}{l}\text { Positive } \\
\text { RANKL }\end{array}$ & $\begin{array}{c}\text { Negative } \\
\text { RANKL }\end{array}$ & Mean $\pm S D$ & SE & $P$ \\
\hline SMA & 13 & 12 & 1 & $57.93 \pm 20.6$ & 5.94 & 0.06 \\
\hline OKC & 14 & 13 & 1 & $43.78 \pm 17.43$ & 4.83 & \\
\hline SMA & 13 & 11 & 2 & $34.68 \pm 20.42$ & 6.15 & 0.09 \\
\hline OKC & 14 & 12 & 2 & $23.96 \pm 10.03$ & 2.89 & \\
\hline
\end{tabular}

degradation of fibrillar collagen, especially type IV collagen which is the major component of basement membrane. ${ }^{[10]}$ Although numerous researches have verified that MMP2 plays an important role in tumor invasion, ${ }^{[11]}$ yet there are limited researches about its behavior in $\mathrm{AB}$ and KOT. The present study as well as the others showed that the high expression and activity of MMP2 is related to the aggressive behavior in both $\mathrm{AB}{ }^{[12-15]}$ and KOT, ${ }^{[16,17]}$ with an overall higher level in the first than in the latter. ${ }^{[12,14,16]}$ There was a strong expression of MMP2 in the stroma of SMA and KOT, which is in accordance with other studies, ${ }^{[18,19]}$ although one study observed the opposite. ${ }^{[15]}$ The presence of MMPs in the tumor stroma could be attributed to tumor induction since neoplastic cells express the protein extracellular inducers (EMMPRIN/CD147) on their surface, and this acts as a potent inducer for the production of MMPs by stromal fibroblasts and endothelial cells. ${ }^{[20]}$

Furthermore, the high expression of MMP2 in the odontogenic epithelia of plexiform type and KOT with daughter cysts (KOT with + DC) could suggest more aggressive behavior of plexiform type of $\mathrm{AB}$. KOTs have a tendency to form satellite cysts through 


\begin{tabular}{|c|c|c|c|c|c|c|c|}
\hline Tissue group & Total number & Cells & Positive RANKL & Negative RANKL & Mean $\pm S D$ & SE & $P$ \\
\hline Plexiform AB & 5 & Odontogenic epithelia & 5 & - & $65.1 \pm 23.75$ & 10.62 & 0.34 \\
\hline Follicular AB & 8 & & 7 & 1 & $53.53 \pm 18.65$ & 7.05 & \\
\hline KOT (with negative DC) & 9 & & 8 & 1 & $43.16 \pm 19.57$ & 6.92 & 0.87 \\
\hline KOT (with positive DC) & 5 & & 5 & 0 & $44.78 \pm 15.47$ & 6.92 & \\
\hline Plexiform AB & 5 & Stromal cells & 5 & 0 & $38.44 \pm 25.72$ & 11.5 & 0.56 \\
\hline Follicular AB & 8 & & 6 & 2 & $31.55 \pm 16.70$ & 6.82 & \\
\hline KOT (with negative DC) & 9 & & 7 & 2 & $26.9 \pm 11.0$ & 4.15 & 0.23 \\
\hline KOT (with positive DC) & 5 & & 5 & 2 & $19.86 \pm 7.68$ & 3.43 & \\
\hline
\end{tabular}

AB: Ameloblastoma, KOT: Keratocystic odontogenic tumor, SD: Standard deviation, SE: Standard error, RANKL: Receptor activator of nuclear factor kappa-B ligand, DC: Dentigerous cysts

detachment of epithelial cell lining from the connective tissue wall. This suggests the important role of MMP2 in this detachment. Wahlgren et al. ${ }^{[17]}$ mentioned that MMP2 can induce epithelial migration by fragmenting the basement membrane material laminin-5 gamma-2 chain, which induced migration, tendency to detach from the connective tissue capsule. This molecular behavior has been thought to be responsible for the frequent recurrence of KOT after surgical enucleation.

Assessment of receptor-activated nuclear factor kappa $B$ expression in ameloblastoma and keratocystic odontogenic tumor

RANK, a member of the tumor necrosis factor receptor superfamily, is the signaling receptor for RANKL. RANKL binds to RANK on the surface of preosteoclasts and stimulates the development and activation of osteoclasts.

RANK originating from the epithelium has an effect on bone resorption, cell proliferation, or delaying apoptosis and hence the tumor growth. The present study could indicate greater bone resorption activity in SMA than KOT. The RANK expression in odontogenic epithelia of SMA is significantly higher than in KOT. Tekkesin et al. ${ }^{[9]}$ observed the opposite findings. However, da Silva et al..$^{[5]}$ observed almost the same findings of the present study.

RANK in stromal cells other than osteoclasts and their precursors may have influential effects in several functions, such as immune cell regulation and inhibition of apoptosis of osteoclasts. ${ }^{[6,21]}$ da Silva et al. ${ }^{[5]}$ and Tekkesin et al. ${ }^{[9]}$ showed different levels of positive stroma cells in $\mathrm{AB}$ and $\mathrm{OKC}$; the present study observed similar stromal RANK expression in both SMA and KOT with heavy staining at the periphery of $\mathrm{AB}$ and $\mathrm{KOT}$.
Expression of RANK, in both the epithelial and connective tissue cells of KOTs and $A B$, indicates that RANK plays a role in local bone resorption of both lesions.

Assessment of receptor-activated nuclear factor kappa $B$ ligand expression in ameloblastoma and keratocystic odontogenic tumor

RANKL is a membrane-bound protein found on osteoblastic and activated T-cells. RANKL binds to RANK on the surface of preosteoclasts and stimulates the development and activation of osteoclasts. Osteoprotegerin (OPG) is a soluble decoy receptor for RANKL that inhibits the pro-osteoclastogenic interaction between RANK and RANKL, thereby inhibiting bone resorption. ${ }^{[22]}$ The RANKL, RANK, and OPG system have been shown to be abnormally regulated in several malignant osteolytic pathologies, including neoplastic and nonneoplastic odontogenic lesions. The enhanced RANKL expression or decreased OPG levels play an important role in tumor-associated bone destruction. ${ }^{[23]}$ OPG and RANKL have also been detected in periodontal ligament cells and their expression are considered to play a role in osteoclastogenesis and bone resorption in periodontal diseases. ${ }^{[24]}$

RANKL expression in the present study confirmed the findings of previous studies where tumor cells and stroma could act as a source of this osteoclastogenic factor. This indicates that RANKL-producing tumor cells of $A B$ and cystic cells of KOT are crucial for osteoclastogenic behavior. The results of the present study also showed that both factors RANK and RANKL had higher ratio when comparing SMA to KOT. This would account to more aggressive nature and higher rate of recurrence in $A B$ than KOT. ${ }^{[5,6,9,25]}$ This fact could be also true when 
comparing plexiform pattern with other histological subtypes of SMA and KOT. ${ }^{[26]}$ There is no known link in the pathway of synthesis, mechanism of action, overexpression of MMP2, and the RANK and RANKL in both SMA and KOT. ${ }^{[27]}$ MMP2 role of action is mainly degradation of extracellular matrix, while RANKL and RANK are involved in mechanism of how the tumor expands in the bone, through stimulation proliferation and activation of osteoclast and hence bone resorption. ${ }^{[28]}$ Bone resorption mediated by activation of RANK and RANKL signalling pathway and matrix degradation by acivation of MMP2 pathway in $A B$ and KOT will identify the aggressive bilogical behavior of both lesions. The fact that RANKL is required for osteoclast development suggests that agents that inhibit its activity may be therapeutic. This has provided the rationale for the development of targeted molecular therapy with the ability to modulate RANK-induced osteoclastogenesis.

\section{CONCLUSION}

The high expression of MMP2, RANK, and RANKL is related to the biological behavior of $A B$ and KOT and may indicate close behavior of KOT to $A B$, which reinforce the possibility of its recent classification as an odontogenic tumor. In addition, tumor epithelial cells of plexiform $A B$ and epithelial nests or satellite microcyst-associated KOT exhibited distinct stronger expression of these markers compared with follicular $\mathrm{AB}$ and KOT without microcyst or epithelial nests, respectively. This could reveal a more aggressive behavior of these types of lesions.

\section{Financial support and sponsorship}

Nil.

\section{Conflicts of interest}

There are no conflicts of interest.

\section{REFERENCES}

1. Mendenhall WM, Werning JW, Fernandes R, Malyapa RS, Mendenhall NP. Ameloblastoma. Am J Clin Oncol 2007;30:645-8.

2. Barnes L, Eveson JW, Reichart P, Sidransky D. Pathology and Genetics of Head and Neck Tumours: Odontogenic Tumours. World Health Organization Classification of Tumours. Ch. 6. Lyon: IARC Press; 2005. p. 283-328.

3. Lacy DL, Timms E, Tan HL, Kelley MJ, Dunstan CR, Burgess T, et al. Osteoprotegerin ligand is a cytokine that regulates osteoclasts differentiation and activation. Cell 1998; 93:165-76.

4. Andrade FR, Sousa DP, Mendonça EF, Silva TA, Lara VS, Batista AC, et al. Expression of bone resorption regulators (RANK, RANKL, and OPG) in odontogenic tumors. Oral Surg Oral Med Oral Pathol Oral Radiol Endod 2008;106:548-55.

5. da Silva TA, Batista AC, Mendonça EF, Leles CR, Fukada S,
Cunha FQ, et al. Comparative expression of RANK, RANKL, and OPG in keratocystic odontogenic tumors, ameloblastomas, and dentigerous cysts. Oral Surg Oral Med Oral Pathol Oral Radiol Endod 2008;105:333-41.

6. Sandra F, Hendarmin L, Kukita T, Nakao Y, Nakamura N, Nakamura S, et al. Ameloblastoma induces osteoclastogenesis: A possible role of ameloblastoma in expanding in the bone. Oral Oncol 2005;41:637-44.

7. Docherty AJ, Murphy G. The tissue metalloproteinase family and the inhibitor TIMP: A study using cDNAs and recombinant proteins. Ann Rheum Dis 1990;49 Suppl 1:469-79.

8. Visse R, Nagase H. Matrix metalloproteinases and tissue inhibitors of metalloproteinases: Structure, function, and biochemistry. Circ Res 2003;92:827-39.

9. Tekkesin MS, Mutlu S, Olgac V. The role of RANK/RANKL/OPG signalling pathways in osteoclastogenesis in odontogenic keratocysts, radicular cysts, and ameloblastomas. Head Neck Pathol 2011;5:248-53.

10. Creemers JW, Ines Dominguez D, Plets E, Serneels L, Taylor NA, Multhaup G, et al. Processing of beta-secretase by furin and other members of the proprotein convertase family. J Biol Chem 2001;276:4211-7.

11. Poulsom R, Pignatelli M, Stetler-Stevenson WG, Liotta LA, Wright PA, Jeffery RE, et al. Stromal expression of $72 \mathrm{kda}$ type IV collagenase (MMP-2) and TIMP-2 mRNAs in colorectal neoplasia. Am J Pathol 1992;141:389-96.

12. Zhang B, Zhang J, Huang HZ, Chen WL, Tao Q, Zeng DL, et al. Inhibition of ameloblastoma invasion in vitro and in vivo by inhibitor of metalloproteinase-2 activity. J Oral Pathol Med 2009;38:731-6.

13. Zhong M, Han YP, Wang J, Li ZJ, Bao G, Yue YL, et al. Expression of matrix metalloproteinases and tissue inhibitor of metalloproteinase in ameloblastoma. Shanghai Kou Qiang Yi Xue 2003;12:427-31.

14. Wang A, Zhang B, Huang $\mathrm{H}$, Zhang L, Zeng D, Tao Q, et al. Suppression of local invasion of ameloblastoma by inhibition of matrix metalloproteinase-2 in vitro. BMC Cancer 2008;8:182.

15. Khalifa GA, Shokier HM, Abo-Hager EA. Evaluation of neoplastic nature of keratocystic odontogenic tumor versus ameloblastoma. J Egypt Natl Canc Inst 2010;22:61-72.

16. Meghji S, Henderson B, Bando Y, Harris M. Interleukin-1: The principal osteolytic cytokine produced by keratocysts. Arch Oral Biol 1992;37:935-43.

17. Wahlgren J, Väänänen $A$, Teronen $\mathrm{O}$, Sorsa $\mathrm{T}$, Pirilä E, Hietanen J, et al. Laminin-5 gamma 2 chain is colocalized with gelatinase-A (MMP-2) and collagenase-3 (MMP-13) in odontogenic keratocysts. J Oral Pathol Med 2003;32:100-7.

18. Zhong M, Li ZJ, Wang J, Yue YL, Bao G. The study of the invasive biologic behavior of ameloblastoma. Zhonghua Kou Qiang Yi Xue Za Zhi 2004;39:45-8.

19. Kumamoto H, Yamauchi K, Yoshida M, Ooya K. Immunohistochemical detection of matrix metalloproteinases (MMPs) and tissue inhibitors of metalloproteinases (TIMPs) in ameloblastomas. J Oral Pathol Med 2003;32:114-20.

20. Sternlicht MD, Werb Z. How matrix metalloproteinases regulate cell behavior. Annu Rev Cell Dev Biol 2001;17:463-516.

21. Page G, Miossec P. RANK and RANKL expression as markers of dendritic cell-T cell interactions in paired samples of rheumatoid synovium and lymph nodes. Arthritis Rheum 2005;52:2307-12.

22. Stejskal D, Bartek J, Pastorková R, Růzicka V, Oral I, Horalík D, et al. Osteoprotegerin, RANK, RANKL. Biomed Pap Med Fac Univ Palacky Olomouc Czech Repub 2001;145:61-4.

23. Tay JY, Bay BH, Yeo JF, Harris M, Meghji S, Dheen ST, et al. Identification of RANKL in osteolytic lesions of the facial skeleton. J Dent Res 2004;83:349-53.

24. Kanzaki H, Chiba M, Shimizu Y, Mitani H. Dual regulation of osteoclast differentiation by periodontal ligament cells through RANKL stimulation and OPG inhibition. J Dent Res 2001;80:887-91.

25. Oka S, Kubota Y, Yamashiro T, Ogata S, Ninomiya T, Ito S, et al. Effects of positive pressure in odontogenic keratocysts. J Dent Res 2005;84:913-8.

26. Qian Y, Huang HZ. The role of Rankl and MMP-9 in the bone resorption caused by ameloblastoma. J Oral Pathol Med 2010;39:592-8.

27. Kumamoto H, Ohki K, Ooya K. Expression of p63 and p73 in ameloblastomas. J Oral Pathol Med 2005;34:220-6.

28. Boyle WJ, Simonet WS, Lacey DL. Osteoclast differentiation and activation. Nature 2003;423:337-42. 